\title{
The Research on Quality Change Effect of Digital Economy Enabled Manufacturing Industry
}

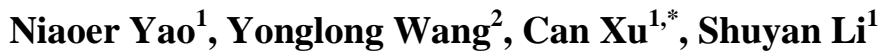 \\ ${ }^{I}$ Ningbo University of Finance and Economics, Ningbo, Zhejiang, China \\ ${ }^{2}$ Zhejiang Yuexiu University, Shaoxing, Zhejiang, China \\ *corresponding author.
}

\begin{abstract}
High-quality development of manufacturing industry is the key to leading the high-quality development of China's economy. The paper analyzes the mechanism and effect of the quality change of China's manufacturing industry enabled by digital economy. And then, it is considered that the basic pattern of China's manufacturing industry is that the manufacturing industry is large but not strong. As a result, quality change could focus on the intensive margin on the basis of strengthening and expanding the margin. However, the quality change of manufacturing industry enabled by digital economy is a complicated process. Therefore, the quality change of manufacturing industry would give full play to the decisive role of market mechanism while giving better play to the role of the government. The focus of policy could focus on incentives and synergy that are conducive to promoting the digital transformation of the manufacturing industry.
\end{abstract}

Keywords: Digital economy, Quality change, Dual margin, Global value chain, Incentive synergy.

\section{Introduction}

The technological revolution interacts with the industrial revolution, and the manufacturing industry is an important intersection of the technological revolution and the industrial revolution. At present, the digital economy with the core of new-generation information technology applications such as big data, cloud computing, artificial intelligence, Internet of Things, and blockchain has been advanced deeply. The general view is that the digital economy represents advanced productivity and new development directions. After experiencing the baptism of the three-industrial revolution, the manufacturing industry is experiencing the profound baptism of the digital economic revolution. The integration of digital economy and manufacturing is not only the internal logic of the development of the digital economy, but also the inevitable choice for the high-quality development of the manufacturing industry. The academic circle has carried out extensive and in-depth research on this, and there are mainly the following two key topics:

The first one is that the integration of the digital economy and the manufacturing industry and the transformation of manufacturing quality. Digital economy integration is the internal mechanism of manufacturing quality change. Hu Zhijian [1] (2018) discussed three ways of integrating the digital economy and manufacturing, including the integration of production methods, the integration of technological systems, and the integration of industrial organizations. Li Mingwei [2], Du Yunsu [3], Yu Donghua [4], et al. (2019) especially emphasized the integration of the digital economy and manufacturing "chain", and promoted the integration of value chains through digital economy to empower industrial chain and supply chain collaborative innovation. It can greatly enhance the development resilience of the manufacturing industry and expand the future growth space. Based on the analysis of digital economy integration methods and enabling effects, Yin Weihua [5] (2019) has believed that manufacturing quality change is a comprehensive quality change. It is a complex process that restricts productivity changes and production relations changes. In addition, Ni Hongfu [6] (2019) and others have discussed the global value chain and supply chain reform, Liu Liwei [7] (2012), Huo Xin [8] (2020), Chen Jin [9] (2018) and others have discussed quality Change etc.

ISSN: 0010-8189

(C) CONVERTER 2020

www.converter-magazine.info 
The second topic is related to smart manufacturing issues. Intelligent manufacturing is a key system for quality change and it is also a core element of the empowerment of the digital economy. Wang Xiwen [10] (2015), Jia Genliang [11] (2016), Han Jiangbo [12] (2017) and others have elaborated on the development direction of China's smart manufacturing which have based on the development trend of the new round of China's scientific and technological revolution. Dai Keqing and Cai Ruilin [13] (2020) have discussed the breakthrough path of intelligent manufacturing service transformation which has based on the perspective of shared services. From the perspective of human-cyber-physical system (HCPS), Wang Baicun et al. [14] (2020) have discussed the development and evolution of intelligent manufacturing and the main features of the new generation of intelligent manufacturing based on the concept of "the integration of IT application with industrialization ".

The comparative advantages of China's manufacturing industry have been mainly concentrated in two important aspects: low cost and low price. In order to fully stimulate the inherent competitiveness of these two comparative advantages, China's manufacturing industry has taken a quantitative growth path characterized by capacity expansion and low-end manufacturing. At the same time, an export-oriented and international trade cycle. Actually, China has the world's largest complete manufacturing system. However, most of China's manufacturing industry has still been embedded in the form of "foundry production" in the global value chain system. Even in some high-tech manufacturing fields, China's manufacturing industry mainly has participated in the global division of labor by a horizontal professional way [15]. Thereinto, labor-intensive manufacturing, capital-intensive manufacturing, knowledge-intensive manufacturing, and intelligent manufacturing coexist, low-end manufacturing and mid-to-high-end manufacturing coexist, and low-tech manufacturing and high-tech manufacturing coexist. The prevailing view is that it is a manufacturing system with endowment heterogeneity, low-end manufacturing dominance, quantitative growth, and dual margins. Compared with the manufacturing industry in developed countries, the basic pattern of my country's manufacturing industry is large but not strong, and the quality gap in the high-end manufacturing sector is still relatively obvious.

Based on a summary of existing research, the effects of the digital economy, the integration mechanism of the digital economy and the manufacturing industry, and the path selection of the digital economy to empower the quality of the manufacturing industry have been generally revealed. In fact, there is no complete embeddedness research on the special complex structural system of China's manufacturing industry. As a result, there are two important research shortcomings: Firstly, the differentiated selective empowerment has not been fully considered for the differentiated structure of China's manufacturing industry. Secondly, too much attention has been paid to the extended margin of manufacturing quality change. Therefore, for a long period of time, the core issue of the development of China's manufacturing industry is how to use the power of the digital economy to better solve the vertical squeeze while cracking the low-end lock-in.

\section{Empirical and Analysis of the Effect of Digital Economy Empowering Manufacturing Quality Reform}

\subsection{Model Construction and Variable Interpretation}

According to the understanding of the quality characteristics of China's manufacturing industry, the enabling mechanism and realization mechanism of the digital economy, this article interprets the digital economy's enabling manufacturing quality transformation effect as a binary marginal structure including "expansion effect" and "intensification effect". And economic growth has been regarded as an explanatory variable that empowers the quality change effect of the manufacturing industry. The global value chain effect, the quality ladder effect, and the total factor productivity effect have been selected as the explanatory variables. These quality effects have represented the key connotations and important characteristics of the quality reform of China's manufacturing industry. The logic of the empirical analysis is: digital economy development $\rightarrow$ formation of a growth driver $\rightarrow$ promotion of manufacturing quality reform $\rightarrow$ realization of a comprehensive quality upgrade of the manufacturing industry. Based on it, this article has constructed the following empirical analysis model: 
EFFECT_Digecodev $\alpha+\beta_{1} G_{1-} C_{1-}$ Position $_{\text {ind }}+\beta_{2} G C_{2-}$ Position $_{\text {ind }}+\beta_{3}$ QUA $_{1-}$ ladders $_{\text {ind }}+\beta_{4}$ QUA $_{2-}$ ladders $_{\text {ind }}+\beta_{5} T E P_{\text {ind }}+\delta$

In the formula, $\alpha, \beta i, \delta$ to be estimated coefficients. The definition, explanation and related data of each variable are as follows:

(1) EFFECT_Digecodev represents the growth index of digital economy. Three important driving forces have been produced by the digital economy, namely: technological driving force, quality driving force and structural driving force. The growth of the digital economy has opened up a wide range of application prospects and new path choices for the quality change of the manufacturing industry. The digital economy development of China has generally experienced three stages: the initial development stage (2000-2010), the integrated development stage of industrialization and industrialization (2010-2014), and the deep digital development stage (since 2015). It is generally acknowledged that "Internet promotion $\rightarrow$ Integration of industrialization and industrialization $\rightarrow$ Made in China 2025" represents the roadmap and direction of China's digital economy development. Currently, China has become the world's second largest digital economy country which only ranks after the United States.

(2) $G V C_{1-}$ Position $_{\text {ind }}$ and $G V C_{2-}$ Position $_{\text {ind }}$ respectively represent the global value chain position index of China's low- and medium tech and high-tech manufacturing industries. The reason why the location indexes have been distinguished by two types is that the digital economy has obvious differences in the empowerment of manufacturing at different technological levels. According to the viewpoint put forward by Koopman et al. [16], it indicates that the industry is more fully competitive in the global value chain system if the GVC position index of an industry in a country is larger. Namely, the industry has higher quality efficiency. Domestic scholars such as Lu Yue [17] (2019), Ni Hongfu [6] (2019) and others have conducted extensive and in-depth research on the global value chain location index of China's manufacturing industry which based on the Koopman theory. The article has used the definition of global value chain location index by Koopman et al. and comprehensively absorbed the representative research results of China's manufacturing GVC location index by the above-mentioned Chinese scholars.

(3) $Q U A_{1-}$ ladders $_{\text {ind }}$ and $Q U A_{2}$ ladders $_{\text {ind }}$ respectively represent the quality ladder of China's low- and medium-tech and high-tech manufacturing industries. The reason why the quality ladders have been distinguished by two types is that the quality ladder and technology level of China's manufacturing industry have formed an asymmetric structure. According to the viewpoint of the quality ladder theory, the distribution law of different product production has been roughly consistent with the manufacturing technical capability and the difference in the characteristics of factor endowment of a country's manufacturing industry. With the changes of these two factors, the position of a country's manufacturing industry in the quality ladder changes accordingly. The quality ladder theory has explained the correlation between technological progress and economic growth, and the quality ladder and total factor productivity. The quality ladder has been a full display of quality advantages, and the improvement of the quality ladder has indicated the direction of continuous upgrading of the industry or product. The improvement of the quality ladder requires both endogenous and exogenous driving forces. And then, digital economic innovation based on a new round of information technology revolution has been considered the most important endogenous driving force.

(4) $T E P_{\text {ind }}$ represents the total factor productivity of the manufacturing industry. Total factor productivity has been an important manifestation of the high-quality growth of modern manufacturing. Although total factor productivity could not be explained by one or some fixed factors, the formation mechanism still has some identifiable key influencing factors found from the practice of modern economic growth. For instance, technological innovation, resource allocation, division and specialization of labor, reform of growth mode, advanced industrial structure, economies of scale, innovation in organization and management, etc. 
The data has showed that: (1)Before 2015, the data related to China's digital economy growth index used the "informatization integration index" provided by the "Data Map of China's Integration of Industrialization and Industrialization (2017)" as an alternative. Since 2015, the data has been replaced by actual growth data provided by the "China Digital Economy Development Report (2017)", and the above data has been normalized based on empirical research. (2)China's manufacturing global value chain position index is derived from WTO-"TiVA database" and collated according to relevant research literature of some Chinese scholars. (3)The quality ladder and total factor productivity data of China's manufacturing industry are mainly based on the research literature of some Chinese scholars. (4)The time series of empirical analysis in the paper is from 2000 to 2018.

\subsection{Empirical Analysis}

First of all, the article has used Generalized Least Squares (GLS) to make a preliminary estimation of the model, and the estimation results have been shown in Table 1. The possible existence of multiple collinearities, heteroscedasticity and variable endogeneity between variables have been considered, the paper further has used the generalized moment estimation (GMM) method for regression. Finally, according to the practice of related scholars such as Yu Donghua [4] and others, the related robustness tests have been performed by the DAD method. The regression results have been shown in Figure 1 and Table 2.

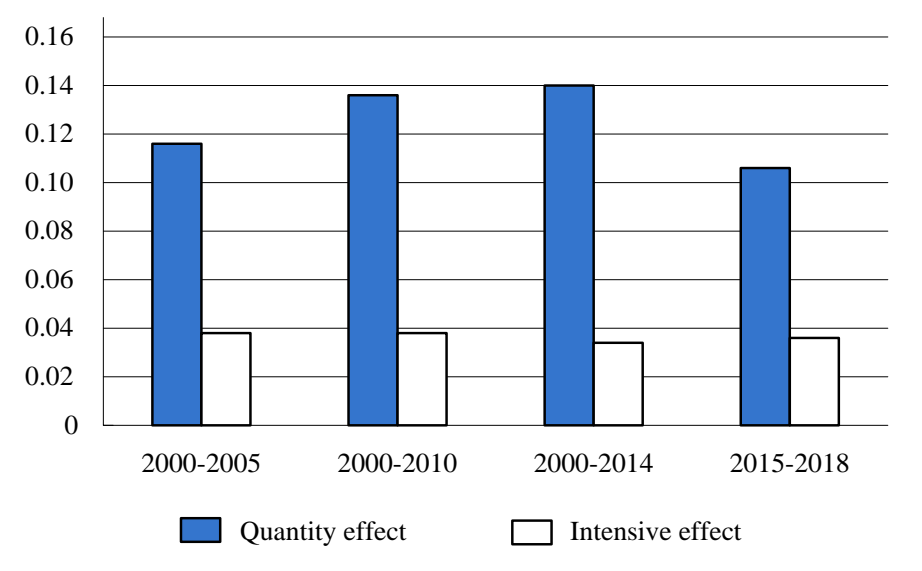

Fig 1: The Dual Marginal Effect of China's Manufacturing Quality Reform

The empirical analysis has showed: the overall effect analysis. At present, the quality reform of China's manufacturing industry which has been enabled by digital economy is still mainly focused on quantity effect (expanding margin). Namely, it mainly concentrates on the global value quantity participation effect and the quality ladder effect. These two effects are relatively obvious. For the intensive effect (intensive margin), such as the position effect of global value chain, total factor productivity effect and supply chain collaborative innovation effect are not obvious. As shown in Figure 1, during the period 2000 to 2014, the expansion effect of China's manufacturing quality reform has showed an upward characteristic. Since 2015, with the deepening development of the digital economy, although the expansion effect has shown a decline, the intensive effect has not shown a simultaneous increase. This characteristic trend maintains basic consistency with China's digital economy roadmap. The article believes that the main reason for the formation of this characteristic trend is that the path dependence of low-end manufacturing, which is mainly characterized by low technology, locks or blocks the effective embeddedness mechanism of quality innovation by digital economy.

Sector effect analysis. The quality effect of digital economy empowerment on the low-tech manufacturing sector is weaker than that on the high-tech manufacturing sector, as shown in Table 2. Taking the improvement of total factor productivity as an example, it is only 0.32 in medium and low-tech sectors, but it reaches 1.98 in high-tech 
sectors, a difference of more than 6 times. This paper argues that the main reason for the formation of the feature is the different structure of factor intensity of the two types of manufacturing sectors. Low-tech manufacturing is dominated by labor intensification, in which numbers are the key or core production factors. The way to integrate with labor factors is relatively narrow, and the innovation potential of digital intensification has been hindered in the increase of labor productivity. The high-tech manufacturing sector is dominated by technology and capital intensification. In this structure, digital elements have multiple ways to combine with technology or capital. The innovative potential of digital intensification could work to a greater extent. Obviously, it is beneficial to foster new business forms, new models, and new growth points.

Table 1 Estimation results of the effects of digital economy empowerment quality change (GLS)

\begin{tabular}{|c|c|c|c|c|}
\hline $\begin{array}{l}\text { EXPLAINED } \\
\text { VARIABLE }\end{array}$ & $2000-2005$ & $2000-2010$ & $2000-2014$ & 2015-2018 \\
\hline$G_{1-}$ Position $_{\text {ind }}$ & $\begin{array}{l}0.038 * * \\
(0.0017)\end{array}$ & $\begin{array}{l}0.031 * * \\
(0.0055)\end{array}$ & $\begin{array}{c}0.021 \\
(0.0118)\end{array}$ & $\begin{array}{c}0.018 \\
(0.0123)\end{array}$ \\
\hline$G_{2-} C_{2}$ osition $_{\text {ind }}$ & $\begin{array}{c}0.005 \\
(0.0048)\end{array}$ & $\begin{array}{c}0.031 \\
(0.0036)\end{array}$ & $\begin{array}{c}0.027 \\
(0.0138)\end{array}$ & $\begin{array}{l}0.041^{*} \\
(0.0134)\end{array}$ \\
\hline$Q U A_{1-}$ ladders $_{\text {ind }}$ & $\begin{array}{c}0.010 \\
(0.0033)\end{array}$ & $\begin{array}{c}0.039 \\
(0.0028)\end{array}$ & $\begin{array}{l}0.055^{* * *} \\
(0.0137)\end{array}$ & $\begin{array}{c}0.048 \\
(0.0133)\end{array}$ \\
\hline$Q U A_{2-}$ ladders $_{\text {ind }}$ & $\begin{array}{l}0.064 * * \\
(0.0023)\end{array}$ & $\begin{array}{c}0.034 \\
(0.0056)\end{array}$ & $\begin{array}{l}0.036^{*} \\
(0.0132)\end{array}$ & $\begin{array}{c}0.028 \\
(0.0134)\end{array}$ \\
\hline$T E P_{\text {ind }}$ & $\begin{array}{c}0.037^{*} \\
(0.0027)\end{array}$ & $\begin{array}{c}0.036 \\
(0.0036)\end{array}$ & $\begin{array}{c}0.033 \\
(0.0123)\end{array}$ & $\begin{array}{l}0.034 * * \\
(0.0131)\end{array}$ \\
\hline $\mathrm{R}^{2}$ & 0.0555 & 0.0621 & 0.4397 & 0.3901 \\
\hline
\end{tabular}

Note: ***, **, * indicate statistically significant at the level of $1 \%, 5 \%$, and $10 \%$, respectively. Numbers in parentheses indicate statistical standard errors.

Table 2 Regression analysis results of mass effects driven by digital economy (GMM)

\begin{tabular}{|c|c|c|c|}
\hline $\begin{array}{c}\text { EXPLAINED } \\
\text { VARIABLE }\end{array}$ & Low- and medium-tech sector effects & High-tech sector effect & Combined effect \\
\hline GVC $_{1-}$ Position $_{\text {ind }}$ & $0.8143(11.72)$ & $1.1288^{*}(17.52)$ & $0.4482 * *(13.12)$ \\
\hline GVC $_{2-}$ Position $_{\text {ind }}$ & $0.4634 * *(6.32)$ & $1.3862 * *(2.64)$ & $1.2452 * * *(6.92)$ \\
\hline$Q U A_{1-}$ ladders $_{\text {ind }}$ & $0.7451 *(12.08)$ & $1.4491 * * *(12.88)$ & $1.781 *(12.65)$ \\
\hline$Q U A_{2}$ ladders $_{\text {ind }}$ & $0.1229 *(3.07)$ & $1.5938^{*}(6.29)$ & $0.3313 *(5.63)$ \\
\hline TEP $_{\text {ind }}$ & $0.3152 * * *(9.25)$ & $1.9791 *(2.34)$ & $1.1858 *(5.91)$ \\
\hline $\mathrm{R}^{2}$ & 0.3650 & 0.3732 & 0.4346 \\
\hline
\end{tabular}

Note: $* * *, * *, *$ indicate statistically significant at the level of $1 \%, 5 \%$, and $10 \%$, respectively. Numbers in parentheses indicate statistical standard errors.

Analysis of marginal effects. Firstly, in the direction of the expansion margin, the low- and medium-tech manufacturing sector shows that the global value chain location effect is stronger than the quality ladder effect. However, the quality ladder effect of the high-tech manufacturing sector is stronger than the global value chain ISSN: 0010-8189 
location effect of it. Secondly, in the direction of intensive marginal, there is no significant differences between the two types of manufacturing sectors. The paper believes that the main reasons for the formation of this pattern of marginal effects are: in the first place, China's low - and medium-technology manufacturing sector participates in and is embedded in the global division of production in the form of contract manufacturing, which has a relatively sufficient quality ladder. Although the global value chains are involved in the higher degree, but the position index is the lower. It is mainly reflected in horizontal specialization value chain, and position upgrading is sensitive to innovation drive. The next, China's high-tech manufacturing sector mainly participates in and is embedded in the global division of labor through direct production. Although it has a high position index, the quality ladder is low, which is mainly reflected in the vertical specialization value chain. The quality ladder migration is sensitive to innovation drive. Moreover, the transformation of the enabling quality of digital economy depends on the reconstruction of factor intensity. The enablement of number as a key factor of production is restricted by labor enablement and capital enablement. Capital empowerment is more flexible in the integration of digital resources than labor empowerment. The digital intensification of low-tech manufacturing sector is often difficult to construct an effective embedment mechanism because of the structural inertia of labor enablement. This is also an in-depth problem that must be solved in the digital transformation of my country's low-end manufacturing industry at present and in the future. There are also the current and future deep problems which China's low-end manufacturing industry digital transformation might be solved.

\section{The Analysis of Digital Economy Empowering Manufacturing Quality Change Governance}

The quality transformation of the manufacturing industry enabled by digital economy is not a simple action process, but a complex action process that is interrelated and mutually restricted by many factors. Objectively, there are some important relationship structure behaviors and the systematic mechanism of interaction. As a result, both in theory and in practice, it has the logic of governance. First of all, theoretically, the digital economy is a new kind of economy that runs through unprecedented new theories, new knowledge, new ideas, new business forms and new development models. The transition from product economy to digital economy is not a complete and simple linear knowledge transfer. The governance of digital economy is a brand-new theoretical topic. Secondly, in practice, on the one hand, a significant increase in uncertainty has been caused by digitization of economy, which also has brought about a continuous increase in complexity and risk, it means new challenges. In this sense, the core of governance is how to stabilize supply chain, try to avoid setbacks, and how to reduce the loss of efficiency caused by circuitous paths. On the other hand, although China has entered a socialist market economy, marketization is not sufficient. In the absence of institutional arrangements, effective supervision and good industrial ecology, a series of market failures such as externalities, opportunism, and moral hazard would inevitably occur. In this sense, the core of governance is how to improve quality and efficiency. Based on the complexity and diversity empowered by the digital economy, quality change governance is also a complex structure. The article only uses the digital economy to empower the transformation of the manufacturing global value chain as an example.

Gereffi (2006) et al. [18] have believed that the long-term quantitative growth path of the manufacturing industry in developing countries has formed a lock-in effect on the upgrade of its global value chain. As a result, how to break this lock-in pattern has become the core task of manufacturing quality reform in developing countries. On this basis, scholars have proposed and constructed two important mechanisms for the global value chain upgrade of the manufacturing industry in developing countries: the embedded mechanism and the alternative mechanism (as shown in Figure 2 and Figure 3). It has been believed that technological empowerment is the key path of the embedded mechanism and advocates the priority of the embedded mechanism.

Value added

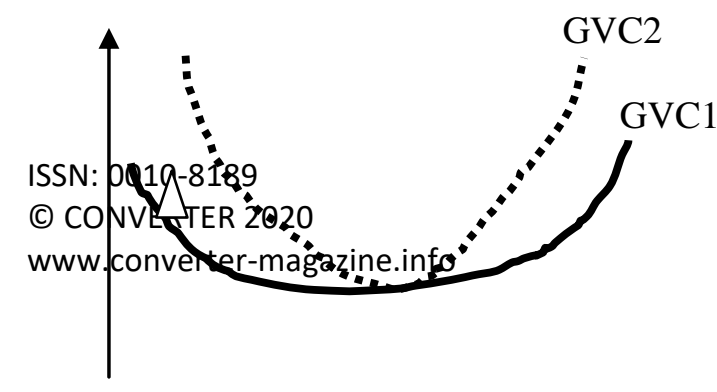

Value added

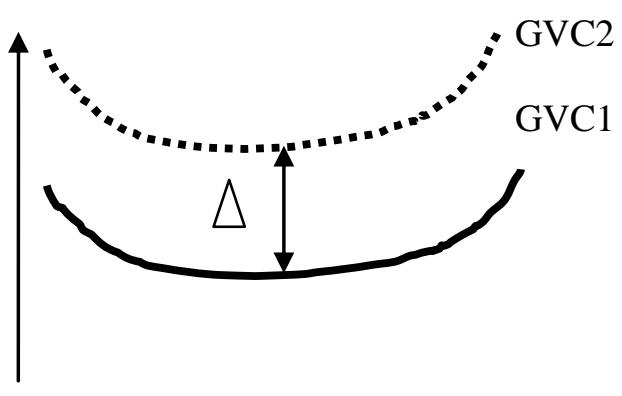




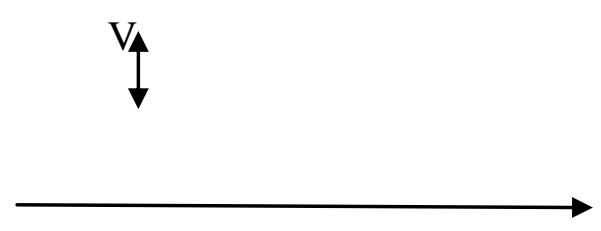

Value Chain Activities

Fig. 2: Global Value Chain Embedded Upgrade
$\mathrm{V}$

\author{
Value Chain Activities
}

Fig. 3: Alternative Upgrading of Global Value Chains

Source: Gereffi \& Fredrick (2006). Illustration: in Figure 2, alternative upgrade means that the production factors of the digital economy are linked to the non-production value-added activities in the global division of labor (mainly at the ends of the smile curve). With digitized advanced technology to replace the traditional nonproductive value-added activities, the two ends of the value chain rise. Illustration: in Figure 3, embedded upgrade means that the digital economy enters both manufacturing activities and non-productive value-added activities, and the global value chain rises.

The article believes that both the embedded mechanism and the alternative mechanism might be actively governed because of the complex pattern of China's manufacturing industry. Taking resource allocation as an example, when digital economy empowerment is put into a resource mismatch structure, it cannot form an incentive for total factor productivity, but inhibit it. The paper argues that the digital economy enables the quality change of manufacturing industry, at least two important aspects of the effective governance structure need to be formed: one aspect is about the choice of the focal point of digital economy empowerment, which not only affects the key direction of digital economy empowerment, but also affects the orientation of quality reform. It is generally believed that the choice of focal points could mainly focus on many aspects such as resource allocation research and development of innovative capacity and production mode reform. On this basis, the paper emphasizes and insists that the choice of focal points would be based on full consideration of the interaction of multiple factors and follow the synergistic principle of quality change, efficiency change and power change. The other aspect is about the realization mechanism of digital economy enabling quality change, which involves complex mechanisms such as iteration and fusion innovation. The article emphasizes and adheres to three directions:

The first one is digital intensification. Freeman and other scholars believe that the manufacturing industry in developing countries is highly labor intensive, while capital and technology intensive are relatively low. The factor intensity structure contains relatively large capital and technological potential, at the same time, the factor intensity structure provides sustainable growth space for the intensive creation of key production factors. At present, China's manufacturing industry is still dominated by labor-intensive manufacturing. It will be possible to introduce digital as a key or core production factor into the production process of China's manufacturing industry. And then, the integration of digital and traditional production factors (such as labor, capital, etc.) could promote digital intensification. It is possible to reconstruct the production function of manufacturing industry and lead and drive China's manufacturing industry into digital-intensive manufacturing. Finally, the total factor productivity of China's manufacturing industry would be improved.

The second one is the iteration of digital technology. The research shows that the evolution of the previous technological revolution and industrial revolution will form the iteration of new technological community to old technological community. The result of the iteration is that the technological foundation of the whole economy (manufacturing) has undergone major improvements, and at the same time, a series of economic changes and quality change effects have been triggered. Currently, the new round of technological revolution has been dominated by digital technologies such as big data, cloud computing, artificial intelligence, the Internet of Things, and blockchain, which has a significant iterative effect on the whole economy, especially the manufacturing sector. However, it must be pointed out that the iterative approach of digital technology over existing technology would not be focused. It is more important to establish and effectively match mechanisms between digital technologies and their applications.

ISSN: 0010-8189

C CONVERTER 2020 
The third is the reconstruction of the microeconomic foundation. Enterprise vitality is usually considered as the basic connotation of the microeconomic foundation. Economists tend to chalk it up to the process by which structure erodes vitality, known as the structural effect. At present, China's manufacturing industry is facing the relatively significant "structural effect." The article believes that digital economy innovation could help solve the problem. A wide range of " Unstructured " effects has been created by empowering the real economy through Internet+, artificial intelligence+, blockchain+, platform+, etc., such as whole industry chain collaboration, embedded configuration, manufacturing execution, e-commerce, etc. Consequently, the new vitality of manufacturing enterprises has been created.

In summary, the quality reform of manufacturing industry enabling by digital economy needs to establish an effective governance structure. It is the important premise and guarantee to realize the enabling effect of digital economy.

\section{Conclusion}

Based on the dual-marginal paradigm, the paper analyzes the effects of digital economy on the quality change of manufacturing industries from both theoretical and empirical aspects. Based on the development pattern of China's manufacturing industry, the key directions of the digital economy's empowerment quality reform have been discussed, and further expands the analysis of three important issues on this basis. Research shows that: Firstly, although China's manufacturing industry has built the world's largest complete system, it still presents a development pattern of endowment heterogeneity, multi-level structure, external circulation dominance, and quantitative growth. Therefore, the empowerment of the digital economy might be actively embedded in the development pattern of China's manufacturing industry, breaking through the low-end lock while breaking through the vertical squeeze. Secondly, based on the overall effect analysis, digital economy empowerment is still mainly focused on the quantitative effect (expansion margin), and the intensive effect (intensification margin) such as the position effect of global value chain, total factor productivity effect, and supply chain collaborative innovation effect are not obvious. Based on the analysis of sectoral effects, the quality effect of digital economy empowerment on the low-tech manufacturing sector is weaker than that of the high-tech manufacturing sector. Based on the analysis of marginal effects, the position effect of global value chain is stronger than the quality ladder effect in the low- and medium-tech manufacturing sector, and the quality ladder effect is stronger than the position effect in the high technology manufacturing sectors. Thirdly, the development pattern of the manufacturing industry transforms from the outer circulation dominated to the inner circulation dominated, and it is an inevitable choice for the domestic and international dual circulations mutually promote the new development pattern. Therefore, it is necessary to fully promote the supply chain circulation, production circulation and market circulation. Fourth, based on the diversity empowered by the digital economy, quality change governance might be strengthened.

Based on the above research conclusions, the article believes that it is necessary to give full play to the decisive role of the market mechanism while giving better play to the role of the government for promoting the empowerment effect of the digital economy. The focus of the policy could focus on incentives and synergy that are conducive to promoting the quality change of the manufacturing industry. And a variety of policy such as fiscal, tax, financial, insurance and technological services could be comprehensively utilized to increase the support for the digital transformation of the manufacturing industry. The Internet + and artificial intelligence + might be full used to explore new models and new business formats for digital transformation development. Shortcomings in the industrial chain, supply chain, value chain, service chain, and technology chain have been complemented. As a result, the manufacturing industry's dependence on low-cost labor and other traditional factors of production has been broken, and the lock-in and squeeze of manufacturing in developed countries has been broken. And then, the core competitiveness of the digital economy reform has been actively constructed.

\section{Acknowledgement}

ISSN: 0010-8189

(C) CONVERTER 2020 
1. Fund assistance: Funding for key projects of major humanities and Social Sciences in Colleges and universities of Zhejiang Province (Project No. 2018GH012)

2. Fund assistance: National and Regional Research Key Projects of the Ministry of Education: Deepen research on key directions and paths of APEC global value chain cooperation (Project No. 19GBQY001).

\section{References}

[1] Z.J. Hu, "Three major changes in the manufacturing value chain driven by the digital economy and China's countermeasures," Science and Technology of China, vol. 7, pp. 1-2, 2018.

[2] M.W. Li, "A research on the driving force and mode of the integration and development of 'Internet+ Manufacturing Industry'," Journal of Xinyang Normal University, vol. 1, pp. 46-50, 2019.

[3] Y.S. Du, Z.L. Jiang, "China's integration into GVCs and its evolving trend," International Business Research, vol. 1, pp. 18-23, 2019.

[4] D.H. Yu, "The influence mechanism of embedded global value chains on the transformation and upgrading of China's manufacturing industry," Reform, vol. 3, pp. 50-59, 2019.

[5] W.H. Yin, "The participation level and position in global value chains of China's high-tech Industry," World Economy Studies, vol. 7, pp. 64-72, 2016.

[6] H.F. Ni, "A review of the theory and application of position in global value chain," Journal of Zhongnan University of Economics and Law, vol. 3, pp. 105-117, 2019.

[7] W.L. Liu, "The quality ladders of trading products in the Chinese manufacturing sector," China Industrial Economics, vol. 11, pp. 58-70, 2012.

[8] X. Huo, "Global manufacturing quality Competition: basic pattern, driving factors and development countermeasures," Intertrade, vol. 4, pp. 87-96, 2020.

[9] J. Chen, N. He, "The upgrading path and countermeasures of China's manufacturing industry under high quality development," Business Economy, vol. 10, pp. 44-52, 2018.

[10] X.W. Wang, "Intelligent manufacturing: The main orientation of the new round of industrial revolution," Renming Luntan Xueshu Qianyan, vol. 19:, pp. 68-79, 2015.

[11] G.L. Jia, "The third industrial revolution and industrial intellectualization," Social Sciences in China, vol. 6, pp. 87-106, 206, 2016.

[12] J.B. Han, "Intelligent industrialization: A new perspective of the study of industrialization development paradigm," The Economist, vol. 10, pp. 21-30, 2017.

[13] K.Q. Dai, R.L. Cai, "Sharing service innovation: Breakthrough path in manufacturing enterprises," Science \& Technology Progress and Policy, vol. 10, pp. 115-138, 2020.

[14] B.C. Wang, B. Yi, Z.Y. Liu, Y. Zhou, Y.H. Zhou, "Evolution and state-of-the-art of intelligent manufacturing from HCPS perspective," Computer Integrated Manufacturing Systems, vol. 10, pp. 121-139, 2020.

[15] Y.L. Wang, "Strategic construction of 're-manufacturing' and its effect on China," The Economist, vol. 11, pp. 97-104, 2017.

[16] X.Z. Yi, H.M. Zhou, K. Robert, "Globalization challenges, international economic and trade governance system reform and China's participation," Journal of Shanghai University of International Business and Economics, vol. 27, no. 6, pp. 5-10, 2020.

[17] Y. Lv, "Length of global value chain and innovation of manufacturing enterprises," Journal of Zhongnan University of Economics and Law, vol. 3, pp. 118-126, 2019.

[18] F. Gereffi, "Quality ladders and in the theory of growth," The review of economic studies, vol. 58, no. 1, pp. 57, 2006. 